\title{
Twenty years of ribosome assembly and ribosomopathies
}

\author{
JONATHAN R. WARNER \\ Department of Cell Biology, Albert Einstein College of Medicine, New York, New York 10461, USA
}

During the 20 years of RNA extraordinary progress has been made in the study of ribosomes, beyond that of ribosome structure, which will be well covered by others.

\section{Ribosome assembly}

One can argue that in 1968 Nomura and colleagues set back the field of ribosome assembly by showing that a bacterial ribosome could be assembled from its constituent rRNA and ribosomal protein (RP) molecules with no help from any catalytic factors. Yet shortly thereafter we found that HeLa prerRNA was complexed with numerous proteins that were not incorporated into the final ribosome, and suggested that many catalytically acting factors were involved in ribosome assembly. Only decades later did the techniques of yeast genetics and of TAP purification/Mass Spectrometry allow the labs of Woolford, Baserga, Tschochner, and many others to identify the catalytic molecules involved, and to show that they are necessary for the production of ribosomes. During the past 20 years it has become clear that in yeast more than 160 proteins are responsible for controlling the endoand exo-nuclease activity needed to form the four rRNAs, for the appropriate folding of the four rRNAs, and for the assembly of the ribosomal proteins on and within them. While nearly all of the assembly factors identified in yeast have human counterparts, the LaFontaine group has identified an additional hundred or so proteins apparently involved in mammalian ribosome assembly, not surprising since the mammalian pre-rRNA transcript is nearly twice the size of the yeast one. In addition, the Kiss laboratory showed that nearly a hundred snoRNA molecules, with associated proteins, are used to establish the many modifications of the rRNAs, through ribose methylation and pseudouridylation, an important early demonstration of the role of RNA-RNA interactions in controlling specific features of RNA processing.

Thus, nearly 300 macromolecules are employed to produce a eukaryotic ribosome! Once again we learn that Nature/Evolution is far more resourceful and clever than we generally anticipate.

Corresponding author: jon.warner@einstein.yu.edu

Article and publication date are at http://www.rnajournal.org/cgi/doi/10. 1261/rna.050435.115. Freely available online through the RNA Open Access option.
Already it is clear that there is a flow of assembly factors onto and off the substrate pre-rRNAs. In some cases placeholders can be identified, e.g., Rlp24 for Rpl24, and Mtr4 for Rpp0, with precise substitutions in a complex ATPdependent process after the nearly complete $60 \mathrm{~S}$ subunits have been exported to the cytoplasm. New cross-linking techniques developed by the Tollervey group and others can pinpoint the sites on pre-rRNA that interact with many of the factors. Coupled with the use of mutants to freeze assembly at any of a number of steps, it is becoming possible to watch the assembly process develop, though with the likelihood that it may take many parallel paths. The intricacy of the cytoplasmic steps of subunit finishing is complemented by the fascinating observation that both $40 \mathrm{~S}$ and $60 \mathrm{~S}$ subunits are subjected to a trial run before being permitted to encounter a mRNA.

Some of the bigger questions remaining: Since the large number of snoRNAs associated with the pre-rRNA would preclude folding the rRNA in its final form, do the many helicases identified as processing factors play a role in the removal of the snoRNAs and in the rearrangement of the final rRNA molecules? Is this an orderly process, perhaps to protect the pre-rRNA from misfolding? Do the several GTPases implicated in ribosome assembly act as ratchets, as they seem to do in translation? Finally, does it have to be so complex? Are there species that have "fast-tracked" the process?

Without doubt, just as the $3 \AA$ structure of the ribosome has been a goldmine of RNA-protein interactions, so the machinery for ribosome assembly promises to be a gold mine for understanding the roles of proteins in manipulating RNA molecules.

\section{Ribosomopathies}

Ribosomes had long been thought of as "housekeeping" elements; ineffective ribosome synthesis should be lethal. Dahl's group shattered this naïve idea by identifying a mutation in the gene encoding Rps19 as the cause of Diamond Blackfan Anemia (DBA). Somehow haploinsufficiency for a single RP gene can lead to the varied pathologies of DBA, not only severe anemia, but also small stature, predisposition to

\footnotetext{
(C) 2015 Warner This article, published in $R N A$, is available under a Creative Commons License (Attribution-NonCommercial 4.0 International), as described at http://creativecommons.org/licenses/by-nc/4.0/.
} 
cancer, cranio-facial and cardiac defects. In the succeeding years it has become clear that the symptoms of DBA can be caused by haploinsufficiency of a gene for any one of at least 10 RPs. There is now an entire field of disease termed the ribosomopathies, a variety of syndromes caused by failure at any of several steps in the production of ribosomes. The incredibly varied penetrance of DBA implies that many "modifier" genes are involved in determining the actual pathology. Remarkably, Bolze has shown that haploinsufficiency for RPSA leads not to anemia, but to asplenia!

The basis of the pathology may be due in part to insufficient ribosomes, leading to reduced protein synthesis, especially of certain key proteins whose mRNAs do not compete well for available ribosomes, perhaps because they depend on an IRES. However, much of the response is far more complex. Imbalance at almost any step in the process of ribosome synthesis triggers a condition termed "nucleolar stress," the accumulation of p53 that leads to cell cycle arrest, and finally, to apoptosis. This can be due to interference with the transcription of rRNA genes by RNA polymerase I, leading to accumulation of ribosomal proteins. Pursuit of this observation has led the Hannan group to promising anticancer drugs. While the accumulation of p53 is due to the affinity of a number of ribosomal proteins for $\mathrm{Hdm} 2$, the ubiquitin ligase that tags p53 for destruction, the story is likely to be more complex, as the Thomas group suggests that both Rpl5 and Rpl11, probably in the RNP that includes 5S rRNA, are needed for the inactivation of Hdm2. Sorting out the genetics of the pathology of RP haploinsufficiency will reveal much about translation, about the central role of ribosome synthesis in cell growth, and about the varied responses of the assembly process to diverse sources of stress.

Furthermore, at least six of the $>200$ assembly factors have been implicated in disease, though with widely varying sites of pathology. Thus, Baserga showed that mutations in CIRH1A, a protein component of an RNP involved in the earliest steps of processing, leads rather specifically to liver disease. Since most assembly factor mutants are recessive, the phenotype is found only rarely, but one predicts that, as the number of mouse knockouts is expanded, we will find that most of the assembly factors are essential, and thus homozygous mutations will lead to human disease in inbred or unlucky individuals. The challenge will be to find cures for diseases attacking this most fundamental element of all cell functions.

Human cells have two types of ribosomes. Little attention has been paid to the mitochondrial ribosomes, whose RNAs are encoded in the mitochondrial genome, while their proteins are encoded in the nuclear genome. Already there are reports of diseases due to mutant genes encoding mitochondrial RPs. The new $3.4 \AA$ structures and the new genetics of mitochondrial ribosomes remain to be fully exploited.

\section{Ribosomal proteins}

The RPs themselves bear watching. The role of specific RPs in the translation of specific mRNAs has been highlighted by Barna's observation that Rpl38 is required for the IRES-dependent translation of a specific subset of HOX genes. For seven of the RP genes there are functioning duplicate copies, three of which are "rescued" pseudogenes. Certain of these duplicates are expressed with great tissue specificity, e.g., Rpl3L in muscle, and Rpl10L in testis. What is their function? Finally, to what extent have the RPs been recruited for nonribosomal functions? The observation by the Fox lab of the recruitment of Rpl13a from the ribosome to the GAIT complex in response to interferon only whets our appetite. 

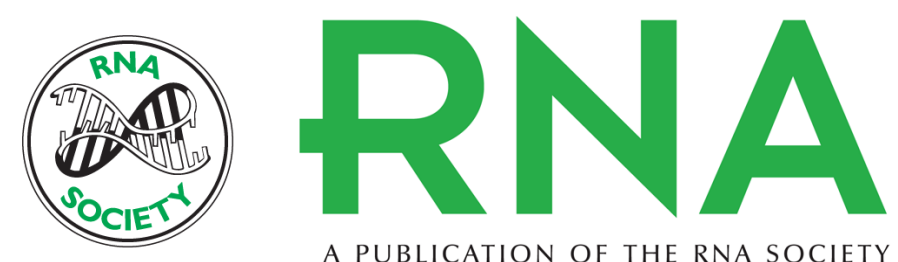

A PUBLICATION OF THE RNA SOCIETY

\section{Twenty years of ribosome assembly and ribosomopathies}

Jonathan R. Warner

RNA 2015 21: 758-759

Open Access Freely available online through the RNA Open Access option.

Creative This article, published in RNA, is available under a Creative Commons License

Commons (Attribution-NonCommercial 4.0 International), as described at

License http://creativecommons.org/licenses/by-nc/4.0/.

Email Alerting Receive free email alerts when new articles cite this article - sign up in the box at the Service top right corner of the article or click here.

To subscribe to $R N A$ go to:

http://rnajournal.cshlp.org/subscriptions

(C) 2015 Warner; Published by Cold Spring Harbor Laboratory Press for the RNA Society 